\title{
JOSÉ E SEUS IRMÃOS EM TRÊS DIMENSÕES: JUDAÍSMO, NAZISMO E IMPACTO NA TEOLOGIA ALEMÃ
}

\section{Antonio Carlos de Melo Magalhães}

(iD) https://orcid.org/0000-0003-0262-3474

Como citar este artigo: MAGALHÃES, A. C. de M. José e seus irmãos em três dimensões: judaísmo, nazismo e impacto na teologia alemã. Todas as Letras - Revista de Lingua e Literatura, São Paulo, v. 23, n. 3, p. 1-11, set./dez. 2021. DOI 10.5935/ 1980-6914/eLETDO2114911

Submissão: outubro de 2021. Aceite: novembro de 2021.

Resumo: O presente artigo propõe uma leitura do romance José e seus irmãos, de Thomas Mann, em três dimensões: as fontes bíblicas judaicas (o livro de Gênesis), o contexto do nazismo e o impacto sobre a exegese alemã da época, lembrando o período de produção e publicação da obra, 1933-1943. Além da leitura do romance, o artigo inclui uma reflexão sobre a relação entre Bíblia e literatura. Com essas três dimensões, o artigo propõe uma reunião de perspectivas que, no âmbito da fortuna crítica sobre a obra, foram mantidas separadas ou em concorrência. Na convergência, proponho a presente abordagem, que oferece uma leitura introdutória da obra, com aspectos ainda não devidamente reunidos pela crítica especializada.

Palavras-chave: Thomas Mann. José e seus irmãos. Gênesis. Nazismo. Exegese. 


\section{INTRODUÇÃO}

$\boldsymbol{O}$ presente artigo retoma estudos iniciados sobre religião na obra de Thomas Mann há uma década, quando abordei, em curto ensaio, uma panorâmica do tema em diferentes obras do autor alemão. Além de ter sido um texto com abordagens mais gerais sobre o conjunto de suas obras, os comentários sobre José e seus irmãos não foram além de notas introdutórias, algo que considero, dez anos depois, inapropriado, especialmente pelo fato de termos uma obra monumental, também no sentido de extensão, com mais de duas mil páginas, com quatro volumes, como é o romance de Thomas Mann.

Ao ler o romance, refleti sobre os elementos estéticos, mas também históricos e conceituais que constituem a obra, e resolvi conduzir a escrita ao cotejamento mais amplo do contexto em que se situa, mas também do trabalho empreendido pelo autor na coleta diligente de material. Tudo isso torna o romance José e seus irmãos uma obra singular, e a singularidade, nesse caso, deve muito à imersão do autor na longa narrativa de José, assim como a encontramos nos capitulos 37 a 50 do livro de Gênesis, um livro que eu nomeio como de inaugurações do humano, pelos muitos usos feitos no contexto do pensamento ocidental, e fundamento para o conjunto da Bíblia Hebraica, pressupondo, óbvio, que o livro é central, não pelo fato de ter sido o primeiro a ser escrito, mas pelo papel estratégico que ocupa na religião e na literatura judaicas.

Ao falar da imersão que a obra de Mann realizou nos textos bíblicos de Gênesis, não pense o leitor que proponho uma leitura que deva ser satisfeita com constatações de intertextualidades, ainda que elas sejam inegáveis. Muito mais do que esse tipo de leitura, pertinente com certeza, mas insuficiente para alguns casos, o que interessa ao meu projeto de leitura dos textos bíblicos não é somente como a Bíblia pode ser encontrada nos vários textos da literatura. A perspectiva que me motiva é outra: analisar as diferentes formas de impacto do texto bíblico, suas potências e intensidades, como características centrais para o seu lugar nessa "estranha instituição chamada literatura" (DERRIDA, 2014). Por conta dessa perspectiva particular, antes de entrar propriamente na obra de Mann, seu contexto e seu processo de escrita, teço alguns comentários sobre esse lugar potente e intenso da Bíblia na casa de muitos aposentos que é a literatura.

\section{A Bíblia COMo/Na literatura}

A Bíblia tem acessos múltiplos, incluindo títulos dos textos, introduções, visão prévia hermenêutica, doutrinamento, as muitas edições, a teologia hegemônica de uma época, as contravenções às hegemonias. Ler um texto é sempre ser guiado por leituras e escolhas, e não é diferente com a Bíblia, um livro profusamente ocupado pelas tradições religiosas e pelas muitas circulações das culturas.

Outro aspecto importante é como lidar com a Bíblia em seu acontecimento literário, sendo ela mesma lida na categoria de texto com gêneros e linguagens tradicionalmente respeitados como marcas e comprovações do literário. A Bíblia é, portanto, segundo essa visão, literatura porque tem gêneros como poesia, parábola, núcleos de prosa, enredos, personagens, além de cumprir os níveis de linguagem, como metáfora, metonimia, tipologias, assim como encontramos em estudos como o de Frye (2004), em seu famoso Código dos códigos. Difícil refutar 
essa constatação, talvez seja até mesmo desnecessário refutá-la. Ainda assim, não vejo nisso o aspecto mais importante. Não é a questão da linguagem tipicamente literária que caracterizaria a força da Bíblia para ser o código que acabou por se tornar na literatura mundial. Trabalho com a tese de que o mais importante nessa relação Bíblia e literatura e Bíblia como literatura - ambas são possíveis -, é a sua intensidade e a excessividade do seu relato. Gosto da proposta que Deleuze e Guattari (2014) fazem em seu livro Kafka: por uma literatura menor, quando indicam que o mais importante não é a ideia de metáfora ou de um arquétipo qualquer, nem a hermenêutica consolidada, tampouco a busca da significância. O mais importante são os "protocolos de experiência" que o texto desencadeia e dos quais se torna parte constitutiva permanente. Tomo distância, portanto, de teses como as de Frye, ainda que as considere importantes para se constatar qualidades intrinsecamente "literárias" do texto bíblico. Contra isso, penso a linguagem de um modo geral, e especificamente a Bíblia, como "sistema de fluxos contínuos de conteúdo e expressão, recortado por agenciamentos maquínicos de figuras discretas e descontínuas" (DELEUZE, 2013, p. 33).

Com semelhante suspeita, tomo distância das teses de Auerbach (2021), quando, em seu clássico Mimesis, ao comparar texto bíblico e texto homérico, acaba por praticar um equívoco ao tentar marcar o texto bíblico como de curta duração. Isso vale para alguns textos, não para todos, e com certeza não para os capítulos de Gênesis destinados a José e seus irmãos.

Outro aspecto importante é a ideia de que a Bíblia é um livro religioso canônico, lembrando que cânone não é uma característica exclusiva da religião, mas ele mesmo é parte do processo que amplia o número de escrituras. Os textos não têm fronteiras absolutas, têm dobras, e as fronteiras são os lugares-limite de sedução e ameaça do outro. A fronteira é uma imagem poderosa para indicar a existência das alteridades circundantes. Uma das dobras do texto é como novos textos invadem o cotidiano, assumem espaços narrativos nas muitas formas da oralidade e produção de imagens. Teríamos que entender o cânone como texto poroso, que se dilata, que carece de constante ampliação, e isso não se dá somente no âmbito da arte. As muitas tradições religiosas em torno do texto atestam essa diversidade e ampliação. Isso provocou conflito, novos textos, ampliação dos antigos, constantes e surpreendentes reescrituras, mas a fonte desse processo, suas causas mais importantes, residem nessa potência do texto bíblico em seus excessos e intensidades.

Destaco somente alguns desses excessos. Com isso quero, no âmbito do presente artigo, indicar algumas das fontes desse longo processo da Bíblia na/como literatura: 1. a ousadia de pensar um Deus transcendente, reunião das muitas divindades. O dilema de estar só e não ter mais assembleia das divindades significa que o uno é, necessariamente, portador do múltiplo e do diverso, uma identidade que reúne as contradições. É diverso, mas é uno, e seu nome é uma descoberta, uma busca. Essas variações em torno do divino são importantes potências do texto bíblico; 2 . outro aspecto importante é uma ideia que cada vez mais advogo: os heróis bíblicos são excessivamente decadentes e virtuosos, ou são expostos em suas decadências e virtudes de uma forma excessiva e intensa. Ninguém sai ileso dessa perspectiva, nem José, um herói virtuoso, mas sutilmente arrogante, excessivamente amado e protegido pelo pai. Ainda que a ideia de herói decadente esteja muito associada, na crítica e teoria literária, ao romance moderno, defendo de que essa característica faz parte das marcas literárias do 
texto bíblico. Os heróis bíblicos são apresentados em suas mais vis contradições e as insinuações em torno de suas performances não se restringem a um punhado de elogios e louvores; 3 . outra característica importante do texto bíblico é o fato de ele ser repleto de imiscibilidades, e isso não somente restrito à ideia de um único Deus, portador de muitos, mas às muitas associações feitas entre figuras e personagens, e aqui não me refiro somente à ideia de figura em Auerbach (1997), em seu belo estudo Figura, quando fala da realização entre figuras do chamado Antigo Testamento e sua atualização e realização no Novo Testamento. Vejo um horizonte mais ancho nas muitas imiscibilidades dos textos bíblicos, não somente numa linha "canônica" de personagens. O texto funciona por ser imiscivel, e isso acontece não somente quando Jesus se torna, por exemplo, o novo Moisés ou novo Adão, mas quando rasuras das culturas se encontram nos textos, quando simbólicas são (re)produzidas de forma surpreendente, imagens de terror e esperança são apresentadas, rastros do mundo político ocupam a escrita, insinuações de práticas são indicadas. Sim, os textos bíblicos vivem de uma imiscibilidade profusa, que nem sempre respeita tipologias padronizadas; 4. o texto bíblico escapa a uma hermenêutica teológica definitiva. Nesse sentido, as hermenêuticas católica, protestante, ortodoxa, da libertação, feminista, racialista, negra encontram abrigos em trechos, em alguma memória. Há, sim, uma memória conservadora na Bíblia, e na tradição posterior, mas há também memórias perigosas, rebeldes. As hermenêuticas, inclusive as vanguardistas, são tentativas de encontrar fundamentos para o ser e o agir, mas o texto guarda potências na feiura e na violência, e se assim não fosse, jamais a Bíblia teria o impacto que teve nas biografias, culturas e civilizações. Não é simplesmente dizer que tudo vale, é reconhecer que tudo existe, está aí. Mais importante que estabelecer uma hierarquia que anunciasse a melhor e a pior leitura da Bíblia, interessa compreender os movimentos ramificados das leituras.

Uma última observação introdutória sobre o texto bíblico: os métodos científicos de leitura da Bíblia, seja na crítica das formas, seja na escola da redação, deram contribuições para a identificação de certos núcleos, mas destruíram os textos como grandes unidades, e as leituras lidam com fragmentos, mas também com as grandes unidades. Há, em alguns casos, um despedaçamento dos textos, uma tirania das origens, e isso os torna reféns de exegetas especialistas que falarão de aspectos filológicos, no máximo das perícopes, mas sempre produzirão curiosidades de formação e, por conta disso, perderão o conjunto, a sequência, o relato, a potência do texto.

\section{José E SEUS IRMÃos: CONTEXTO DO NAZISMO, MITO E A gUESTÃo JUDAICA}

Situemos a publicação do romance (em quatro volumes) em seu tempo: 19331943, lembrando que os primeiros dois volumes ainda foram publicados na Alemanha, sob o poder inicial de Hitler; o terceiro volume, em Viena; o quarto, somente em Estocolmo, em plena guerra. Um romance de mais de duas mil páginas assume, a despeito de acolher diferentes mitos e tradições narrativas, além de fundamentação filosófica complexa, na busca pela "elucidação do segredo da condição humana”, uma dimensão política também pelo período de seu surgimento. O último volume, Joseph, der Ernährer (José, o provedor, também no sentido de quem providencia a comida para garantir a vida), é um texto de intenso diálogo e confronto com a morte de milhares, justamente porque o poder 
constituído não era para a proteção e a garantia da vida, mas para seu extermínio. A questão judaica deveria ser vista, nesse complexo e trágico contexto, também como uma questão cristã e humana, mas o judaísmo precisaria ser resgatado como origem/fonte do cristianismo e da civilização ocidental. Thomas Mann, na fase de preparação do romance, assume esse caráter pendular da herança e presença judaica: as principais vítimas do nazismo fornecem as chances, imagens, personagens para a reconstrução da humanidade, não para confirmar uma origem pura ou ideal, porque o José de Thomas Mann é judeu, egípcio, humano.

A fortuna crítica pouca importância deu a algo central ao processo de escrita do romance: a intensa troca de correspondência de Mann com rabinos, as pesquisas que ele faz sobre a religião e as tradições hermenêuticas judaicas e sobre o Antigo Egito. Faz parte do trabalho do autor a pesquisa em arquivos e documentos históricos. Os romances de Thomas Mann, especialmente José e seus irmãos, foram preparados por longas pesquisas, demonstradas em suas cartas a amigos e acadêmicos. Vejo o romance como conceitual, no sentido de seguir um planejamento de pesquisa e uma concepção de enfrentamento das mazelas de um período.

Algumas correspondências mencionam os vários títulos que ele leu sobre o Antigo Egito e sobre a Bíblia Hebraica. Por outro lado, pouca importância foi dada ao impacto que a obra de Mann teve sobre a exegese alemã, especialmente na de von Rad, um nome de projeção maior na exegese. Minha proposta de leitura privilegia esse entrelugar que o romance José e seus irmãos assume entre judaísmo e cristianismo, um diálogo dificil, mas necessário no contexto do nazismo, o que a obra de Mann acabou por construir de forma singular. Em conferência sobre o objetivo que norteou a escrita da obra, o autor declara: "O mito foi arrancado das mãos do nazismo e humanizado em seus detalhes na linguagem humana. Se as leituras futuras derem importância a isso, então o livro terá alcançado o objetivo de seu autor" (MANN, 1974, p. 658). Acionar a "humanização dos mitos" como projeto foi fruto, em grande parte, desse gesto político de recuperar José e seus irmãos como leitura de um tempo dificil e abertura para decifrar o humano. Contra o destruidor e aniquilador (Hitler), é preciso recuperar a memória do protetor e fornecedor da vida (José). É preciso seguir esses movimentos de extrema rapinagem e ameaça (venda, poço, escravidão), mas chegar aos lugares de recuperação da vida - dos patriarcas fundadores de Israel à decifração do humano, ao futuro de uma humanidade redimida da barbárie. Por um lado, o autor dedica-se à tradição judaica, e um dos exemplos é a importância que o autor alemão deu às tradições escriturísticas do judaísmo. Por outro lado, a recuperação do Egito também para a memória do Ocidente não deixa de ser instigante para o contexto. As alteridades ameaçadas e esquecidas tornam-se protagonistas, e nesse protagonismo emerge a visão de uma humanidade. Israel e Egito, duas memórias turvas de um Ocidente ressentido e de uma Alemanha em plena consolidação do nazismo.

Thomas Mann assume a narrativa de José como mito nos três niveis que estão em sua obra: 1. a narrativa primeira sobre a condição humana - e isso não somente no sentido de origem cronológica, mas pelo alcance e atualidade do mito, por ser um relato que se prolonga com a própria história da humanidade; 2. a narrativa que fala da indissociável relação do humano com o divino, com a sofisticação para indicar os dilemas dessa relação, os conflitos subjacentes, as incertezas assumidas, as promessas feitas; 3. o relato lido como contravenção à 
instrumentalização do mito pelo nazismo. Para Mann, o mito continuava a ser linguagem fundamental, não deveria ser superado pela razão moderna. A tarefa a ser cumprida pelo romance, mas também pela pesquisa, era a de recontar o mito sem a rapina ideológica realizada pelo nazismo. Nesse sentido é que Mann usa a ideia de humanizar o mito, ao retirá-lo dos entulhos de seu tempo. Para Mann (1974, p. 656), os mitos não são somente arcaicos, linguagem depreciada, antessala da história: eles formam origens e guiam destinos. "Mito é fundação da existência. É a estrutura atemporal, a forma religiosa que está na vida a retirar sempre os marcos da existência". "O mito é a atemporal presença" (MANN, 1974, p. 626).

Em torno do conceito de mito é que devemos entender a crítica que Mann fez ao Romantismo. Longe de ser somente uma questão meramente estética, há uma crítica a certo onirismo em torno da terra e do povo nesse movimento. Por sucumbir à ideia de volta à terra, à pátria, ao chão numa ideologia que cada vez mais negava o futuro e desdenhava da vida em sua diversidade.

Desde o início da escrita, chegando às palestras após a publicação, Thomas Mann fazia referência à narrativa de José como um épico da humanidade e um tipo de poesia mundial. Em uma de suas cartas a rabinos, devidamente coletadas em suas Gesammelte Werke (obras completas, 1974), menciona o personagem José como uma canção humana, entoada no mais obscuro dos tempos. Aqui é importante destacar essa visão radicalmente humanista de Mann, mas com o enfoque no religioso. Seria a religião essa transcendência mais humanizante, seria a narrativa religiosa o relato do segredo da condição humana? $\mathrm{Na}$ contramão de uma crítica que se repetia sobre a religião, na volta ao Antigo Egito e à narrativa de José e seus irmãos, Thomas Mann redimensiona o lugar da religião no processo de humanização, entendida, no conjunto da obra de Mann, como a capacidade de sobrevivência digna à tragédia histórica imposta pela barbárie. Longe de ser linguagem da alienação, algo que seria tipicamente moderno, a religião emerge em Thomas Mann como recuperação da memória resistente, portadora de beleza que dá dignidade às existências em situações-limite, como possibilidade de guia para uma vida protegida e protetora.

\section{Algumas abordagens sobre o romance}

I. Romance judaico, assim como o próprio autor via a obra: "é verdade, minha narrativa lembra uma exegese da Torah e uma ampliação, como no Midrash rabino" (MANN, 1974, p. 663), mas também pela recepção significativa em círculos de intelectuais judeus, incluindo estudos que estabeleciam a relação entre o romance e as técnicas narrativas recomendadas pelos mestres do Midrash, de reviver a memória ao recontar as narrativas fundantes. Contudo, há também alusões muito fortes ao Talmud; por exemplo, no segundo volume da obra, quando Thomas Mann fala dos sete motivos para a castidade de José, a sequência é a mesma encontrada no Talmud e os argumentos pouco diferem. Quer dizer, se fôssemos recorrer a uma teoria da intertextualidade entre Gênesis bíblico e romance, teríamos que ampliar essa relação para as muitas técnicas narrativas que se encontram nas hermenêuticas judaicas. Teriamos que ver uma segmentação de intertextualidades, para não ficarmos circunscritos a uma relação direta romance-Bíblia. Mais um aspecto a ser destacado: a técnica narrativa no Midrash de reconhecer as lacunas do texto e preenchê-lo com ampliações dos 
relatos. Textos são para serem expandidos, não somente lidos e observados. Thomas Mann chega a usar uma personagem que não está na Bỉblia, mas no Midrash, para dar a notícia de que José estava vivo e era senhor no Egito. O texto bíblico não se encontra somente em relação episódica com a arte, no caso aqui com o romance de Thomas Mann, mas em sequência de textos, abordagens, ampliação, revisão e associações. As intertextualidades precisariam ser entendidas como bifurcações, em alguns casos, linhas de continuidades, em outros, mas também em descontinuidades e rupturas, e isso tudo não somente no âmbito da arte. A própria tradição religiosa cuidou de desenvolver diferentes estratégias de ocupação e ampliação do texto.

II. Duas narrativas, religiosa e literária (Bíblia e literatura), que dialogam, com singularidades estéticas e apresentam uma visão da "mundanidade do mundo", segundo Gerhard von Rad, no sentido de que as duas narrativas elevam o humano ao seu papel de ação humanizadora e protetora, emancipada não de Deus, mas da barbárie, da fome, da ideologia totalitária. Em von Rad há um tipo de leitura que, positivamente, é tipicamente teológica, sem cair em catequizações apressadas e na retirada da ação humana para legitimar qualquer ação divina. O teólogo alemão reconhece, entre as muitas virtudes do romance de Thomas Mann, a de humanizar para proteger e enfrentar ideologias totalitárias que podem surgir em nome de Deus ou não. Além dessa "mensagem humanista" do romance e do texto bíblico, von Rad retoma a própria exegese alemã, para, a partir do romance, apontar para os equívocos, inclusive os seus, na leitura do texto de Gênesis. A partir da obra de Mann, o exegeta alemão repensa a própria constituição do texto de Gênesis, sua sequência, sem priorizar a fragmentação do texto por conta de suas diferentes origens. É o texto em sua totalidade, na sequência de Gênesis, que deve ser o foco da leitura, não mais as partes, os fragmentos, marca da exegese alemã desse contexto. Aceitar esse pressuposto conduziu von Rad a uma guinada na interpretação do Gênesis, assim como ele deixa indicado em seu artigo ("Aufsatz") originalmente publicado em 1965 em Biblische Josepherzählung und Josephroman, quando retoma uma ideia germinal a ser enfrentada e superada do livro Die Komposition des Hexateuch (18661877), de Julius Wellhausen - a ideia básica de que a narrativa de José seria uma mistura de fontes textuais dispersas mas organizadas como unidade literária. É sob a influência de Thomas Mann que von Rad desloca toda a interpretação da longa narrativa de José para o diálogo com a tradição sapiencial, lembrando que essa tradição está na segunda e terceira fases do desenvolvimento do personagem Deus, e alguns dos resultados de von Rad são extremamente atuais e propõem quatro aspectos como centrais: 1 . Bíblia como literatura; 2 . unidade narrativa do texto; 3 . sentido de humanidade, texto como produção do humano; 4. teologia da criação em José e seus irmãos.

\section{Trechos Do ROMANCE}

Faço somente um limitado recorte de alguns trechos e situações do romance, não caberia no escopo do presente artigo uma discussão detalhada - algo para um ensaio mais longo. Em todas as citações do romance, serão somente mencionadas as páginas da edição em português.

I. O morto do poço vai ao país de deuses que se alimentam dos mortos: "[...] seus mortos são deuses e seus deuses são mortos, e vocês não sabem o que 
significa o Deus vivo”. José estava morto para suas relações afetivas, morto para sua história passada "[...] e o óleo que lhe deram para ungir-se, depois de se ter purificado da poeira da cisterna abandonada, não fora outro senão o óleo que se põe no túmulo ao lado do defunto para que possa ungir-se no outro mundo" (p. 12). "Morto estou para a minha vida antiga" (p. 233). O romance destaca esse ciclo da "morte" de José, desde sua condição de ser amado pelo pai, mas rejeitado pelos irmãos, sua condição de existência ameaçada como escravo, seus dias jogado no poço, que evoca um túmulo de sua condição. A primeira parte dessa jornada é de alguém que foi "sepultado", impedido do convivio com os viventes, recolhido ao submundo da memória e destinado ao esquecimento, que é também, na tradição judaica, talvez, o tipo de morte mais cruel.

II. A ideia que toma conta da narrativa de que a fé de José aponta sempre para a sobrevivência, a proteção, sob os desígnios de Deus: na abertura do segundo volume (José no Egito), José pergunta a Kedma, um dos filhos do senhor que o resgata e se torna um novo pai: "Aonde me leva Deus, enquanto vou em vossa companhia?”, e o rapaz surpreso reage com indignação à arrogância de José, algo que vai se repetir desde o momento em que seus irmãos cultivam ressentimento e inveja. A viagem, para Kedma, seria somente mais uma viagem para a escravidão, um negócio a mais, um corpo a mais vendido para a satisfação dos senhores. A reação de José é guia de muitas outras ocasiões futuras:

- Não penso em tal - respondeu José. - Sei muito bem que vós, meus senhores, estais viajando por vossa conta, para fins que tendes em mira e ides aonde quereis. A minha pergunta não era contra a vossa dignidade e soberania. Mas, vê tu, o mundo tem muitos centros, uma para cada criatura, e em redor de cada criatura ele está situado de modo particular. Tu estás apenas um côvado de distância de mim; no entanto, em volta de ti há um mundo, cujo centro não sou eu, mas tu mesmo. Eu, porém, sou o centro do meu mundo. Portanto, ambos os centros são verdadeiros, quer se trate do teu, quer do meu. O que é certo é que os nossos mundos não distam tanto um do outro que não se possam tocar. De tal modo Deus os impeliu e entrelaçou um no outro que vós, ismaelitas, podeis perfeitamente viajar com independência e seguindo a vossa vontade, indo aonde quiserdes, sem deixardes de ser, nesse entrelaçamento, um meio e um instrumento para eu chegar à minha meta. Por esta razão é que pergunto para onde me levais (p. 10).

Nem sempre é de fácil discernimento onde começa a ação divina e termina a humana, os desígnios sempre estão embaralhados com as singularidades e escolhas: "Entre o terrestre e o celeste a fronteira é móvel e não é necessário mais que pousar o olhar sobre uma aparição para que ele se refranja num aspecto duplo" (p. 239).

III. O futuro assume essa força para lidar com o presente, transpor o amanhã e lidar com o mais poderoso, porque há algo além do poder aparentemente absoluto: "Haverá alguma coisa acima do mais alto? Sim, quando se tem no sangue o sentido de futuro, isto é, do que está acima do amanhã" (p. 309). "É que o futuro é esperança e por bondade foi dado tempo ao homem para viver em expectativa" (p. 310). É importante assinalar esse jogo entre o amanhã e o futuro. O futuro é olhar longínquo, é a esperança da vida que resistirá e continuará, faz parte do núcleo de promessas. A vida não está confrontada somente pelo amanhã, 
pelo imediato devir, mas pela força que a sabedoria pode garantir, apesar dos sete anos de penúria, da longa escravidão, das contingências inquestionáveis.

IV. É preciso entrar no Egito não somente como escravo, mas como o sábio que assume a cultura como forma de sobrevivência, inclusive conviver com coisas proibidas: "Jamais José, o raptado, andara tanto como aqui entre coisas proibidas...” (p. 94), mas no proibido está a diversidade que amplia horizontes e gera outros pertencimentos:

Tudo isso pôde ver José e, pelo caminho, viu ainda outras pessoas de cor daqueles. Aliás viu gente de todos os tons, da cor negra da obsidiana, passando por muitos graus de pardo e amarelo, até o branco cor de queijo. Viu mesmo cabelos amarelos e olhos azuis, caras e trajes de todo talho: viu a humanidade (p. 120).

Nessa citação e em páginas afins do romance, encontramos uma perspectiva fundamental da obra de Thomas Mann: José é o judeu que desceu à morte, deixou de ser escravo para ser senhor bondoso, tornou-se protetor dos famintos e pobres, mas também protótipo de uma nova humanidade, aquela que deveria ser construída não mais pelas hierarquias em torno do humano, mas a que anunciaria a assembleia dos povos sob o manto da sabedoria, da proteção, da vida que se prolonga por administradores sábios, não mais ameaçada pelos que em nome do poder dizimam, ameaçam, roubam a comida das famílias e não planejam um futuro digno para as comunidades humanas. Só vê a humanidade, em sua diversidade e beleza, quem se deixou tomar pela sabedoria que protege a vida e assegura o futuro. José é o mito do passado que enfrenta a ideologia do presente, o humano que anuncia o futuro.

\section{ConClusão}

O romance José e seus irmãos percorre um longo caminho, do Gênesis bíblico, passando pelos muitos textos judaicos, chegando aos redutos de uma experiência brutal e trágica da história da humanidade: a barbárie do nazismo. Romance monumental, com suas mais de duas mil páginas, em quatro volumes, torna-se exemplar de uma literatura conceitual e histórica, construída nos escombros da ascensão e consolidação do nazismo, ao mesmo tempo que se situa numa longa tradição de relatos míticos-bíblicos como uma forma de produzir sentidos que não sejam objetos da rapina política. A Bíblia não é, para Mann, em seu romance, somente base da literatura, é um texto de sabedorias para o futuro, não somente para o amanhã, esse devir imediato, para a dignidade humana, para aqueles que teimam em prever o futuro como reunião dos povos, sem os poderes que obliteram e destroem.

O herói bíblico, o herói do romance, José, no final dos relatos, indica a possibilidade de o ser humano transformar a jornada para a morte, incluindo o poço, a escravidão, a ameaça ao esquecimento, em perdão e novos inícios. José recusa o ódio e a vingança como alternativas mais importantes. Na reconciliação final com os irmãos, José declara a atitude que preserva a vida digna, lembrando que o judeu aqui é sempre o humano a sobreviver. Nesse sentido, a humanidade está projetada em José, não somente como o judeu de qualquer pureza étnica, mas como judeu transformado em egipcio que acolhia a humanidade em 
sua diversidade. A vida de José é ampliada no Egito, nesse país que ele chama de engraçado.

Deverei, pois, para vingar-me dos três dias de castigo que passei no poço, empregar o poder de Faraó que me foi conferido, convertendo em mal o que Deus transformou em bem? Isso me dá vontade de rir! Porque um homem que, contra a razão e o direito, usa do seu poder tão-somente porque o tem é um homem ridículo. Se hoje não o é, sê-lo-á mais tarde. O que nos interessa é o futuro! Amanhã, com o favor de Deus, empreenderemos a nossa viagem de volta ao engraçado país que é o Egito.

Assim thes falou José e todos riram e choraram juntos e estenderam para ele suas mãos e o tocaram, e José também estendendo as suas, os acariciou. E assim termina a linda história inventada por Deus de José e seus irmãos (MANN, 2000a, p. 535).

Talvez o livro encerre com um convite, para que descubramos países engraçados, que nos ensinem a rir, por sabermos guardar alguma alegria para o futuro, a fim de que cheguemos não ressentidos e tomados de ódio aos amanhãs.

\section{JOSEPH AND HIS BROTHERS: JUDAISM, NAZISM AND THEIR IMPACT ON GERMAN EXEGESIS}

Abstract: This article proposes a reading of the novel Joseph and his brothers, by Thomas Mann, in three dimensions: Jewish biblical sources (the book of Genesis), the context of nazism and the impact on German exegeses at the time, recalling the period of production and publications of the work, 1933-1943. In addition to reading the novel, the article includes a reflection on the relationship between the Bible and literature. With these three dimensions, the article proposes a gathering of perspectives that, in the context of the critical fortune about the work, were kept separate or in competition. In convergence, I propose the present approach, which offers an introductory reading of the work, with aspects that have not yet been properly gathred by the specialized critics.

Keywords: Thomas Mann. Joseph and his brothers. Genesis. Nazism. Exegesis.

\section{REFERÊNCIAS}

AUERBACH, E. Figura. São Paulo: Ática, 1997.

AUERBACH, E. Mimesis: a representação da realidade na literatura ocidental. São Paulo: Perspectiva, 2021.

DELEUZE, G. Conversações. São Paulo: Editora 34, 2013.

DELEUZE, G.; GUATTARI, F. Kafka: por uma literatura menor. Belo Horizonte: Autêntica, 2014.

DERRIDA, J. Essa estranha instituição chamada literatura. Belo Horizonte: UFMG, 2014.

FRYE, N. Código dos códigos: a Bíblia e a literatura. São Paulo: Boitempo, 2004. MANN, T. Der dritte Roman: Joseph in Ägypten. Wien: Bermann-Fischer, 1936. v. 3. 
MANN, T. Der erste Roman: die Geschichten Jaakobs. Berlin: Fischer, 1933. v. 1. MANN, T. Der vierte Roman: Joseph, der Ernährer. Stockholm: Bermann-Fischer, 1943. v. 4.

MANN, T. Der zweite Roman: der junge Joseph. Berlin: Fischer, 1934. v. 2.

MANN, T. Gesammelte Werke in 13 Bänden. Frankfurt a. M.: Fischer, 1974.

MANN, T. José no Egito. Rio de Janeiro: Nova Fronteira, 2000a. v. 2.

MANN, T. José, o provedor. Rio de Janeiro: Nova Fronteira, 2000b. v. 3.

VON RAD, G. A história de José do Egito. Petrópolis: Vozes, 1973.

VON RAD, G. Biblische Josepherzählung und Josephroman. NerkichenVluyn: NeukirchenerVerlag, 1974. 